\title{
PERBAIKAN KUALIATAS AIR HUJAN SEBAGAI AIR BERSIH DENGAN METODE MINERALISASI DAN DESINFEKSI
}

\author{
Rita Dewi Triastianti, Rian Hazilmi
}

INTISARI

\begin{abstract}
Tujuan dari penelitian ini adalah untuk memperbaiki kualitas kadar air hujan dengan rangkaian proses mineralisasi dengan media batuan kapur dan pecahan genteng dilanjutkan dengan proses desinfeksi menggunakan kaporit sehingga dapat mengolah air hujan sebagai alternatif air bersih. Hasil yang didapatkan pada proses mineralisasi adalah $\mathrm{pH}$ sebesar 6,733, Fe sebesar 0,01 mg/l dan kesadahan sebesar $70,63 \mathrm{mg} / 1 \mathrm{CaCO}_{3}$. Sedangkan pada proses desinfeksi didapatkan perbaikan pada konsentrasi total coli dengan efisiensi penurunan sebesar 100\%. Sehingga dari seluruh rangkaian penelitian ini dapat dihasilkan komposisi media terbaik yaitu perbandingan batuan kapur dan pecahan genteng $(45 \mathrm{~cm}: 45 \mathrm{~cm})$ dan dosis terbaik desinfektan kaporit $0,1 \%$ adalah $30 \mathrm{ml} / \mathrm{L}$.
\end{abstract}

\section{IMPROVEMENT OF RAINWATER QUALITY AS CLEAN WATER WITH MINERALIZATION AND DESINFECTION METHODS}

\begin{abstract}
The purpose of this research is to improve the quality of the water content of rain with a series of processes with media mineralization limestone and tile fragments followed by disinfection using chlorine so that it can process the rainwater as an alternative water supply. The results obtained in the mineralization process is $\mathrm{pH}$ of 6.733, Fe of $0.01 \mathrm{mg} / \mathrm{l}$ and hardness of $70.63 \mathrm{mg} / \mathrm{l} \mathrm{CaCO3}$. While at the disinfection process improvement is obtained at a concentration of total coli with a decrease of $100 \%$ efficiency. So the whole series of this study can be produced best media compositions that comparison limestone and tile fragments (45cm: $45 \mathrm{~cm}$ ) and best dose of $0.1 \%$ chlorine disinfectant is $30 \mathrm{ml} / \mathrm{L}$.
\end{abstract}

\section{PENDAHULUAN}

Pada dasawarsa terakhir telah terjadi peningkatan pemanfaatan sumber daya air hujan seiring dengan peningkatan pertumbuhan penduduk dan kemajuan pembangunan di segala bidang. Di Indonesia sendiri sangat dibutuhkan pengolahan air hujan menjadi air bersih karena sumber daya air hujan telah menjadi komoditi ekonomi yang memiliki peran penting dalam menunjang kehidupan masyarakat dalam segala aktivitas yang dilakukannya, 
terutama sebagai sumber air bersih untuk keperluan seharihari bagi penduduk, proses industri, pertambangan, peternakan, irigasi, perikanan dan lain-lain.

Desa Banguntapan, Kecamatan Banguntapan, Kabupaten Bantul, Provinsi DIY terletak antara $07^{\circ} 44^{\prime} 04^{\prime \prime}-08^{\circ}$ $00^{\prime} 27^{\prime \prime}$ Lintang Selatan dan $110^{\circ}$ $12^{\prime} 34^{\prime \prime}-110^{\circ} 31^{\prime}$ 08' Bujur Timur. Menurut klasifikasi iklim Koppen, Bantul memiliki iklim musontropis.

Karakteristik air hujan pada umumnya memiliki $\mathrm{pH}$ rendah (3,0-6,0), mineral rendah, kesadahan rendah, $\mathrm{Fe}$ tinggi $(>0,3)$, serta kandungan organik

\section{TINJAUAN PUSTAKA}

Air bersih adalah salah satu jenis sumber daya berbasis air yang bermutu baik dan biasa dimanfaatkan oleh manusia untuk dikonsumsi atau dalam melakukan aktivitas mereka sehari-hari. Di Indonesia persyaratan air bersih yang disyaratkan pada tiap-tiap golongan, diatur dalam Permenkes Nomor 416 Tahun 1990 tentang syarat-syarat dan pengawasan kualitas air. Adapun syarat-syarat yang harus dipenuhi dalam air bersih adalah sebagai berikut :
a. Persyaratan Fisik
b. Persyaratan Kimia
c. Persyaratan Biologis

yang tinggi (>10). Tapi karakteristik air hujan yang dihasilkan tergantung pada daerah geologis suatu tempat.

Maka dari itu, secara ilmiah ingin dicoba dengan proses filtrasi dan desinfeksi apakah air hujan yang dilewatkan melalui filter dengan media pecahan genteng dan batuan kapur sebagai proses filtasi yang dilanjutkan dengan desinfeksi dapat menambah kandungan mineral, $\mathrm{pH}$ dan kesadahan serta dapat menurunkan kadar $\mathrm{Fe}$ dan total Coliform, sehingga diperoleh air yang setara dengan air bersih dan sesuai dengan baku mutu yang berlaku

Pada umumnya kualitas air hujan cukup bagus namun dapat mengakibatkan kerusakan logam yaitu dengan munculnya korosi/karat. Dari segi bakteriologis relatif bersih tergantung tempat penampungnya. Selain itu khusus untuk daerah perkotaan, umumnya air hujan telah terpolusi oleh debudebu, asap kendaraan bermotor ataupun asap pabrik. (Wuryadi, 1991).

\section{METODE PENELITIAN}

\subsection{Lokasi Penelitian}

Dalam penelitian ini lokasi pengumpulan air sampel di rumah No. 616 RT 23/RW 17 Babadan, 
Dusun VIII Plumbon, Desa Banguntapan, Kecamatan Banguntapan, Kabupaten Bantul, Yogyakarta. Lokasi uji parameter di laboratorium Kampus II Sekolah Tinggi Teknik Lingkungan "YLH" Yogyakarta.

\subsection{Obyek Penelitian}

Obyek penelitian adalah air hujan yang dilakukan di rumah No. 616 RT 23/RW 17 Babadan, Dusun VIII Plumbon, Desa Banguntapan, Kecamatan Banguntapan, Kabupaten Bantul, Yogyakarta

\subsection{Waktu Penelitian}

Penelitian dilakukan mulai bulan Desember 2014 sampai Mei 2015.

\subsection{Data Sekunder}

Berikut merupakan contoh uji analisa parameter air hujan di Laboratorium Teknik Lingkungan Sekolah Tinggi Teknik Lingkungan "YLH" Yogyakarta. Hasil uji ini untuk mengetahui hasil parameter sebagian sampel air hujan agar dapat menentukan komposisi media yang akan digunakan untuk penelitian

\begin{tabular}{|c|c|c|c|}
\hline No & Parameter & Satuan & $\begin{array}{c}\text { Hasil } \\
\text { Pengujian }\end{array}$ \\
\hline 1. & $\mathrm{pH}$ & - & 6,1 \\
\hline 2. & Besi $(\mathrm{Fe})$ & $\mathrm{mg} / \mathrm{L}$ & 0,0 \\
\hline 3. & Kesadahan & $\begin{array}{c}\mathrm{mg} / \mathrm{L} \\
\mathrm{CaCO} 3\end{array}$ & 14,110 \\
\hline
\end{tabular}

\subsection{Variabel Penelitian}

Variabel-variabel dalam penelitian ini terdiri dari :
1. Variabel Terikat :

pH, Kesadahan, Fe dan Coliform

2. Variabel Bebas :

Komposisi media filter pecahan genteng \& batuan kapur $(45 \mathrm{~cm}$ : $45 \mathrm{~cm}, 50 \mathrm{~cm}: 40 \mathrm{~cm}, 55 \mathrm{~cm} \mathrm{:} 35 \mathrm{~cm})$

Dosis densinfektan kaporit $(10 \mathrm{ml} / \mathrm{L}$, $20 \mathrm{ml} / \mathrm{L}, 30 \mathrm{ml} / \mathrm{L}$ )

\subsection{Alat dan Bahan Penelitian}

Alat yang digunakan dalam penelitian ini antara lain :

1. 3 Pipa PVC diameter $20 \mathrm{~cm}$ dengan tinggi $120 \mathrm{~cm}$

2. 1 Bak penampung air sampel dengan volume 120L.

3. 3 buah stop keran dengan diameter 3/4 icnh.

4. 4 buah valve globe dengan diameter $3 / 4$ inch

5. Beaker glass, 9 buah dengan volume $1000 \mathrm{ml}$.

6. Pipet Ukur.

7. Botol gelap steril $1000 \mathrm{ml}$

8. Pipa $3 / 4$ inch

9. Elbow sebanyak 7 buah

10. $\mathrm{T}$ bow sebanyak 2 buah

11. Meteran.

12. Stopwatch

Bahan-bahan yang digunakan dalam penelitian ini :

1. Larutan Kaporit $0,1 \%$

2. Air Hujan

3. Batuan Kapur

4. Pecahan Genteng

\subsection{Tahapan Penelitian}

1. Menyiapkan alat dan bahan. 
2. Pembuatan alat filtrasi

3. Menyiapkan bak filter sebanyak 3 buah, tiap-tiap filter dilakukan 3 kali perulangan.

4. Hasil filtrasi dibawa ke laboratorium Teknik Lingkungan Sekolah Tinggi Teknik Lingkungan "YLH" Yogyakarta untuk mengetahui komposisi filter terbaik.

5. Menyiapkan bak filter dengan komposisi filter terbaik $(45 \mathrm{~cm}$ : $45 \mathrm{~cm})$, tiap-tiap bak filter dilakukan 3 kali perulangan.

4. HASIL PENELITIAN DAN PEMBAHASAN

\subsection{Hasil Penelitian}

\subsubsection{Hasil Penelitian} Perbaikan Kualitas pH, Fe, Kesadahan dan Total coli pada Air Hujan

Karakteristik air hujan pada umumnya memiliki $\mathrm{pH}$ rendah $(3,0-6,0)$, mineral rendah, kesadahan rendah, $\mathrm{Fe}$ tinggi $(>0,3)$, serta kandungan organik yang tinggi (>10), air hujan belum bisa dikatakan layak sebagai air bersih berdasarkan Permenkes RI No 416/Menkes/Per/IX/1990. Untuk memperbaiki kualitas air hujan pada wilayah Babadan, Banguntapan, Bantul Yogyakarta maka dilakukan penelitian mineralisasi dan desinfeksi agar kandungan
6. Hasil filtrasi kemudian dilanjutkan dengan proses desinfeksi menggunakan kaporit $0,1 \%$.

7. Pemberian kaporit $0,1 \%$ dengan dosis 10 $10 \mathrm{ml} / \mathrm{L}, \quad 20 \mathrm{ml} / \mathrm{L}, \quad$ dan 30ml/L dengan 3 kali perulangan pada air hasil filtrasi.

8. Hasil desinfeksi dibawa ke laboratorium Teknik Lingkungan Sekolah Tinggi Teknik Lingkungan "YLH" Yogyakarta untuk mengetahui dosis desinfektan terbaik

parameter diatas bisa memenuhi standar baku mutu air bersih yang telah ditentukan.

Penelitian dilakukan dengan proses mineralisasi yaitu menggunakan batuan kapur dan pecahan genteng serta proses desinfeksi menggunakan kaporit. Pada proses mineralisasi dilakukan perlakuan dengan komposisi media yang berbeda yaitu perbandingan $45 \mathrm{~cm}$ : $45 \mathrm{~cm}, 40 \mathrm{~cm}: 50 \mathrm{~cm}$, dan $35 \mathrm{~cm}$ : $55 \mathrm{~cm}$. Sedangkan pada proses desinfeksi dilakukan perlakuan dengan penambahan dosis kaporit yaitu 10ml/1, 20ml/l dan 30 $\mathrm{ml} / 1$ Masing-masing perlakuan diulangi sebanyak 3 kali.

Hasil penelitian sebelum dilakukan perlakuan dapat 
disajikan dalam tabel sebagai berikut :

Tabel 4.1.1. Hasil Analisa Kualitas Air Baku

\begin{tabular}{|c|c|c|c|c|c|c|}
\hline \multirow[b]{2}{*}{$\begin{array}{l}\mathrm{N} \\
\mathrm{o} \\
.\end{array}$} & \multirow[b]{2}{*}{$\begin{array}{c}\text { Parame } \\
\text { ter }\end{array}$} & \multirow[b]{2}{*}{ Satuan } & \multicolumn{3}{|c|}{ Hasil Perulangan } & \multirow{2}{*}{$\begin{array}{c}\text { Standa } \\
\text { rt } \\
\text { Baku } \\
\text { Mutu }\end{array}$} \\
\hline & & & I & II & III & \\
\hline 1 & $\mathrm{pH}$ & - & 6,1 & 5,8 & 5,7 & $\begin{array}{c}6,5- \\
9,0\end{array}$ \\
\hline 2 & $\mathrm{Fe}$ & $\mathrm{Mg} / \mathrm{L}$ & 0,0 & 0,0 & 0,01 & 1,0 \\
\hline 3 & $\begin{array}{l}\text { Kesada } \\
\text { han }\end{array}$ & $\begin{array}{l}\mathrm{Mg} / \mathrm{L} \\
\mathrm{CaCO}_{3} \\
\end{array}$ & $\begin{array}{c}14,1 \\
10 \\
\end{array}$ & $\begin{array}{c}16,9 \\
51 \\
\end{array}$ & $\begin{array}{c}16,9 \\
51 \\
\end{array}$ & 500 \\
\hline 4 & $\begin{array}{l}\text { Total } \\
\text { Coli }\end{array}$ & $\begin{array}{l}\mathrm{MPN} / 10 \\
0 \mathrm{ml}\end{array}$ & - & 75 & 9 & $\begin{array}{c}50 \\
\text { untuk } \\
\text { bukan } \\
\text { air } \\
\text { perpip } \\
\text { aan, } \\
10 \\
\text { untuk } \\
\text { air } \\
\text { perpip } \\
\text { aan }\end{array}$ \\
\hline
\end{tabular}

Sumber : Data Sekunder, 2015

\subsubsection{Hasil Penelitian Perbaikan Kualitas pH dengan Proses Mineralisasi pada Air Hujan \\ Berikut adalah hasil} penelitian perbaikan kualitas $\mathrm{pH}$ dengan proses mineralisasi pada air hujan yang dapat disajikan dalam tabel sebagai berikut :

Tabel 4.1.2. Data Hasil Analisa pH Sesudah Dilakukan Proses Mineralisasi

\begin{tabular}{|c|c|c|c|c|c|}
\hline \multirow[b]{2}{*}{ No } & \multirow[b]{2}{*}{$\begin{array}{c}\text { Komposisi } \\
\text { Filter } \\
\text { Batuan Kapur : } \\
\text { Pecahan } \\
\text { Genteng }\end{array}$} & \multicolumn{3}{|c|}{ Perulangan } & \multirow[b]{2}{*}{$\begin{array}{c}\text { Rata- } \\
\text { rata }\end{array}$} \\
\hline & & I & II & III & \\
\hline 1. & Awal & \multicolumn{3}{|c|}{5,8} & \\
\hline 2. & $45 \mathrm{~cm}: 45 \mathrm{~cm}$ & 6,8 & 6,6 & 6,8 & 6,733 \\
\hline 3. & $40 \mathrm{~cm}: 50 \mathrm{~cm}$ & 6,5 & 6,3 & 6,3 & 6,367 \\
\hline 4. & $35 \mathrm{~cm}: 55 \mathrm{~cm}$ & 6,0 & 6,0 & 5,9 & 5,967 \\
\hline
\end{tabular}

Sumber : Data Primer, 2015

Dari tabel di atas, dapat diketahui hasil rata-rata dari tiap media filter. Hasil terbaik yaitu pada komposisi batuan kapur : pecahan genteng $(45 \mathrm{~cm}: 45 \mathrm{~cm})$ dengan pH 6,733. Sedangkan pada komposisi batuan kapur : pecahan genteng $(40 \mathrm{~cm}: 50 \mathrm{~cm}$ dan $35 \mathrm{~cm}: 55 \mathrm{~cm}$ ) didapatkan hasil 6,367 dan 5,967.

\subsubsection{Hasil Penelitian Perbaikan Kualitas Fe dengan Proses Mineralisasi pada Air Hujan \\ Berikut adalah hasil} penelitian perbaikan kualitas Fe dengan proses mineralisasi pada air hujan yang dapat disajikan dalam tabel sebagai berikut :

Tabel 4.1.3. Data Hasil Analisa Fe Sesudah Dilakukan Proses Mineralisasi

\begin{tabular}{|c|c|c|c|c|c|}
\hline \multirow[b]{2}{*}{ No } & \multirow{2}{*}{$\begin{array}{c}\text { Komposisi } \\
\text { Filter } \\
\text { Batuan } \\
\text { Kapur : } \\
\text { Pecahan } \\
\text { Genteng }\end{array}$} & \multicolumn{3}{|c|}{ Perulangan } & \multirow[b]{2}{*}{$\begin{array}{c}\text { Rata- } \\
\text { rata }\end{array}$} \\
\hline & & I & II & III & \\
\hline 1. & Awal & \multicolumn{3}{|c|}{0,0} & \\
\hline 2. & $\begin{array}{c}45 \mathrm{~cm} \mathrm{:} \\
45 \mathrm{~cm}\end{array}$ & $\begin{array}{c}0,0 \\
1\end{array}$ & 0,01 & 0,01 & 0,01 \\
\hline 3. & $\begin{array}{l}40 \mathrm{~cm}: \\
50 \mathrm{~cm}\end{array}$ & $\begin{array}{c}0,0 \\
1\end{array}$ & 0,01 & 0,01 & 0,01 \\
\hline 4. & $\begin{array}{l}35 \mathrm{~cm}: \\
55 \mathrm{~cm}\end{array}$ & $\begin{array}{c}0,0 \\
1\end{array}$ & 0,01 & 0,01 & 0,01 \\
\hline
\end{tabular}

Sumber : Data Primer, 2015

Dari hasil tabel di atas, dapat diketahui hasil rata-rata dari tiap media. Pada tiap-tiap komposisi media batuan kapur : pecahan genteng $(45 \mathrm{~cm}: 45 \mathrm{~cm}$, 
$40 \mathrm{~cm}: 50 \mathrm{~cm}$ dan $35 \mathrm{~cm}: 55 \mathrm{~cm}$ )

didapatkan hasil yang sama yaitu

$0,01 \mathrm{mg} / \mathrm{l}$.

\subsubsection{Hasil Penelitian Perbaikan Kualitas Kesadahan dengan Proses Mineralisasi pada Air Hujan}

Berikut adalah hasil penelitian perbaikan kualitas kesadahan dengan proses mineralisasi pada air hujan yang dapat disajikan dalam tabel sebagai berikut :

Tabel 4.1.4. Data Hasil Analisa Kesadahan Sesudah Dilakukan Proses Mineralisasi

\begin{tabular}{|c|c|c|c|c|c|}
\hline \multirow[b]{2}{*}{$\begin{array}{l}\mathrm{N} \\
\mathrm{o}\end{array}$} & \multirow{2}{*}{$\begin{array}{c}\text { Komposisi } \\
\text { Filter } \\
\text { Batuan } \\
\text { Kapur : } \\
\text { Pecahan } \\
\text { Genteng } \\
\end{array}$} & \multicolumn{3}{|c|}{ Perulangan } & \multirow{2}{*}{$\begin{array}{c}\text { Rata- } \\
\text { rata }\end{array}$} \\
\hline & & I & II & III & \\
\hline 1. & Awal & \multicolumn{3}{|c|}{16,951} & \\
\hline 2. & $\begin{array}{c}45 \mathrm{~cm}: \\
45 \mathrm{~cm}\end{array}$ & $\begin{array}{c}67,80 \\
5 \\
\end{array}$ & $\begin{array}{c}76,28 \\
1 \\
\end{array}$ & 67,805 & 70,630 \\
\hline 3. & $\begin{array}{r}40 \mathrm{~cm}: \\
50 \mathrm{~cm}\end{array}$ & $\begin{array}{c}42,37 \\
8 \\
\end{array}$ & $\begin{array}{c}50,85 \\
3 \\
\end{array}$ & 59,329 & 50,853 \\
\hline 4. & $\begin{array}{c}35 \mathrm{~cm}: \\
55 \mathrm{~cm}\end{array}$ & $\begin{array}{c}25,42 \\
7\end{array}$ & $\begin{array}{c}25,42 \\
7\end{array}$ & 21,189 & 24,014 \\
\hline
\end{tabular}

Sumber : Data Primer, 2015

Dari hasil tabel di atas, dapat diketahui hasil rata-rata dari tiap media filter. Pada komposisi media batuan kapur: pecahan genteng $(45 \mathrm{~cm}: 45 \mathrm{~cm})$ didapatkan hasil konsentrasi kesadahan yaitu 70,630 mg/l $\mathrm{CaCO}_{3}$, sedangkan pada komposisi media filter $(40 \mathrm{~cm}$ : $50 \mathrm{~cm}$ dan $35 \mathrm{~cm}: 55 \mathrm{~cm})$ didapatkan hasil yaitu 50,853 $\mathrm{mg} / \mathrm{l} \mathrm{CaCO}_{3}$ dan 24,014 mg/l $\mathrm{CaCO}_{3}$.

Setelah dilakukannya proses mineralisasi pada air hujan, maka didapatkan komposisi media terbaik yang yaitu komposisi media batuan kapur : pecahan genteng $(45 \mathrm{~cm}$ : $45 \mathrm{~cm}$ ) ditinjau dari perbaikan kualitas konsentrasi pH 6,733, Fe $0,01 \mathrm{mg} / \mathrm{l}$ dan kesadahan $70,630 \mathrm{mg} / \mathrm{l} \mathrm{CaCO}_{3}$. Komposisi media filter ini $(45 \mathrm{~cm}: 45 \mathrm{~cm})$ akan digunakan untuk tahapan proses desinfeksi.

\subsubsection{Hasil Penelitian Konsentrasi Fe Setelah Melalui Proses Mineralisasi dan Desinfeksi \\ Berikut adalah hasil} penelitian konsentrasi Fe dengan proses mineralisasi dengan perbandingan komposisi media batuan kapur dan pecahan genteng $(45 \mathrm{~cm}: 45 \mathrm{~cm})$ dan telah melalui proses desinfeksi dapat disajikan dalam tabel sebagai berikut : 
Tabel 4.1.5. Data Hasil Analisa Konsentrasi $\mathrm{Fe}$ Setelah Melalui Proses Mineralisasi dan Desinfeksi

\begin{tabular}{|c|c|c|c|c|c|}
\hline & \multirow{2}{*}{$\begin{array}{c}\text { Dosis } \\
\text { Kaporit } \\
0,1 \% \\
\end{array}$} & \multicolumn{3}{|c|}{ Perulangan } & \multirow[b]{2}{*}{$\begin{array}{l}\text { Rata- } \\
\text { rata }\end{array}$} \\
\hline & & I & II & III & \\
\hline 1. & Awal & \multicolumn{3}{|c|}{9} & \\
\hline 2. & $10 \mathrm{ml}$ & 3 & 7 & 3 & 4,333 \\
\hline 3. & $20 \mathrm{ml}$ & 3 & 3 & 3 & 3 \\
\hline 4. & $30 \mathrm{ml}$ & 0 & 0 & 0 & 0 \\
\hline
\end{tabular}

Sumber : Data Sekunder, 2015

Dari hasil tabel di atas, dapat diketahui hasil konsentrasi $\mathrm{Fe}$, setelah melalui proses mineralisasi dengan komposisi media batuan kapur : pecahan genteng $(45 \mathrm{~cm}: 45 \mathrm{~cm})$, kemudian dilanjutkan dengan proses desinfeksi kaporit $0,1 \%$ dengan dosis $10 \mathrm{ml} / \mathrm{l}$ didapatkan hasil $\quad 0,02 \quad \mathrm{mg} / \mathrm{l}, \quad 20 \mathrm{ml} / \mathrm{l}$ didapatkan hasil $0,0 \mathrm{mg} / \mathrm{l}$ dan $30 \mathrm{ml} / \mathrm{l}$ didapatkan hasil $0,0 \mathrm{mg} / \mathrm{l}$.

\subsubsection{Hasil Penelitian Perbaikan Kualitas Total Coli dengan Proses Desinfeksi pada Air Hujan}

Berikut adalah hasil penelitian perbaikan kualitas total coli dengan proses desinfeksi pada air hujan yang dapat disajikan dalam tabel sebagai berikut :
Tabel 4.1.6. Data Hasil Analisa Total Coli Sesudah Dilakukan Proses Desinfeksi

\begin{tabular}{|c|c|c|c|c|c|c|}
\hline \multirow{2}{*}{$\begin{array}{l}\mathrm{N} \\
\mathrm{o} .\end{array}$} & \multirow{2}{*}{$\begin{array}{l}\text { Dosis } \\
\text { Kaporit }\end{array}$} & \multicolumn{3}{|c|}{ Perulangan } & \multirow{2}{*}{$\begin{array}{c}\text { Rat } \\
\text { a- } \\
\text { Rat } \\
\text { a }\end{array}$} & \multirow{2}{*}{$\begin{array}{c}\text { Satua } \\
\mathrm{n}\end{array}$} \\
\hline & & I & II & III & & \\
\hline 1. & Awal & \multicolumn{3}{|c|}{0,01} & & $\mathrm{Mg} / \mathrm{l}$ \\
\hline 2. & $10 \mathrm{ml} / \mathrm{L}$ & 0,02 & 0,02 & 0,02 & $\begin{array}{c}0,0 \\
2\end{array}$ & $\mathrm{Mg} / \mathrm{l}$ \\
\hline 3. & $20 \mathrm{ml} / \mathrm{L}$ & 0,0 & 0,0 & 0,0 & 0,0 & $\mathrm{Mg} / \mathrm{l}$ \\
\hline 4. & $30 \mathrm{ml} / \mathrm{L}$ & 0,0 & 0,0 & 0,0 & 0,0 & $\mathrm{Mg} / \mathrm{l}$ \\
\hline
\end{tabular}

Sumber : Data Primer, 2015

Dari hasil diagram 4.1.5. diatas, dapat diketahui hasil ratarata dari tiap-tiap dosis kaporit. Pada dosis 10ml/l didapatkan hasil total coli yaitu 4,333 MPN/100ml, sedangkan pada dosis 20ml/1 dan 30ml/1 didapatkan hasil $3 \mathrm{MPN} / 100 \mathrm{ml}$ dan 0 MPN/100ml. Dosis terbaik pada proses desinfeksi adalah dengan dosis 30ml/l yang dapat menurunkan total coli hingga 0 MPN/100ml.

\subsubsection{Hasil Efisiensi Dosis Kaporit Terhadap Perbaikan Konsentrasi Total Coli}

Berikut merupakan data hasil analisa efisiensi dosis kaporit terhadap perbaikan konsentrasi total coli, dapat disajikan pada tabel sebagai berikut : 
Tabel 4.1.7. Efisiensi Dosis

Kaporit Terhadap

Total Coli

\begin{tabular}{|c|c|c|c|c|c|c|}
\hline \multirow{2}{*}{ No } & \multirow{2}{*}{$\begin{array}{c}\text { Dosis } \\
\text { Kaporit } \\
0,1 \%\end{array}$} & \multicolumn{3}{|c|}{ Perulangan } & \multirow{2}{*}{$\begin{array}{c}\text { Rata- } \\
\text { rata }\end{array}$} & \multirow[b]{2}{*}{ Efisiensi } \\
\hline & & I & II & III & & \\
\hline 1. & Awal & & 9 & & - & \\
\hline 2. & $10 \mathrm{ml}$ & 3 & 7 & 3 & 4,333 & $66,692 \%$ \\
\hline 3. & $20 \mathrm{ml}$ & 3 & 3 & 3 & 3 & $66,667 \%$ \\
\hline 4. & $30 \mathrm{ml}$ & 0 & 0 & 0 & 0 & $100 \%$ \\
\hline
\end{tabular}

Sumber : Data Primer, 2015

Dari hasil diagram 4.1.6. di atas, dapat diketahui hasil efisiensi rata-rata dari tiap-tiap dosis kaporit terhadap perbaikan konsentrasi total coli. Pada dosis kaporit 10ml/1 didapatkan hasil efisiensi sebesar $67 \%, 20 \mathrm{ml} / 1$ sebesar $66,67 \%$, dan $30 \mathrm{ml}$ sebesar $100 \%$.

\subsection{Pembahasan}

Setelah dilakukan penelitian, didapatkan komposisi media terbaik yaitu perbandingan kapur dan pecahan genteng $(45 \mathrm{~cm}: 45 \mathrm{~cm})$. Karena pada komposisi tersebut, terjadi perbaikan $\mathrm{pH}$ dan kesadahan yang lebih baik dibanding komposisi lainnya, sedangkan konsentrasi $\mathrm{Fe}$ hasil pada tiap-tiap komposisi media sama. Hal ini terjadi karena pada perbandingan $45 \mathrm{~cm}: 45 \mathrm{~cm}$, komposisi batuan kapur lebih banyak dibanding dengan perbandingan komposisi lainnya sehingga terjadi perbaikan yang lebih baik terhadap $\mathrm{pH}$ dan kesadahan. Sedangkan pada media pecahan genteng hanya terjadi peningkatan konsentrasi $\mathrm{Fe}$ cukup kecil dikarenakan kontak air terhadap media yang terlalu singkat.
Terjadi perbaikan terhadap parameter $\mathrm{pH}$ dan kesadahan dikarenakan pada kandungan batuan kapur memiliki kandungan kalsium karbonat $\left(\mathrm{CaCO}_{3}\right), \quad$ magnesium karbonat $\left(\mathrm{MgCO}_{3}\right)$, kalsium sulfat $\left(\mathrm{CaSO}_{4}\right)$, magnesium sulfat $\left(\mathrm{MgSO}_{4}\right)$ dan sebagainya (Chemistry06-lieva, 2009). Sehingga media batuan kapur dapat memperbaiki $\mathrm{pH}$ dan kesadahan, karena batuan kapur mengandung senyawa mineral $\mathrm{CaCO}_{3}$ dan $\mathrm{MgCO}_{3}$. Semakin tinggi kadar kapur pada proses mineralisasi, maka semakin tinggi juga peningkatan $\mathrm{pH}$ dan kesadahan.

Pada konsentrasi $\mathrm{Fe}$ terjadi perbaikan, ini dikarenakan pada pecahan genteng mengandung kumpulan mineral-mineral silikat hidrous yang mengandung unsurunsur alumina, besi, alkali dan alkali tanah. Tetapi pada treatment ini, konsentrasi Fe hanya meningkat 0,01 $\mathrm{mg} / \mathrm{l}$ saja, dikarenakan kontak air terhadap media hanya sebentar sehingga kandungan mineral yang terdapat pada pecahan genteng tidak memberikan perbaikan konsentrasi yang begitu besar. Konsentrasi $\mathrm{Fe}$ bisa naik karena media batuan pecahan genteng, akan tetapi konsentrasi $\mathrm{Fe}$ kembali turun,dapat dilihat pada tabel 4.1.5. Hal ini diakibatkan terjadinya proses oksidasi oleh kandungan kaporit, sebelum kandungan klor/kaporit mengoksidasi konsentrasi total coli, senyawa pada klor lebih dulu 
mengoksidasi kandungan mineral yang terdapat dalam air.

Setelah dilakukan treatment desinfeksi, didapatkan dosis terbaik yang ditinjau dari perbaikan konsentrasi total coli yaitu pada dosis 30ml/1, karena semakin tinggi kandungan kaporit maka semakin efektif dalam proses desinfeksi. Pada dosis 30ml/l juga menghasilkan efisensi tertinggi dalam perbaikan konsentrasi total coli yaitu mencapai $100 \%$, dapat dilihat pada tabel 4.1.7. Adapun mekanisme kaporit dapat dilihat pada reaksi berikut :

\section{$\mathrm{Ca}(\mathrm{OCl})_{2}+\mathrm{H}_{2} \mathrm{O} \longrightarrow \mathrm{Ca}(\mathrm{OH})_{2}+$ $2 \mathrm{HOCl}$$$
\mathrm{HOCl} \rightleftarrows \mathrm{H}^{+}+\mathrm{OCl}^{-}
$$

$\mathrm{HOCl}$ dan $\mathrm{OCl}^{-}$merupakan sisa khlor yang bersifat sebagai desinfeksi dan efektif dalam membunuh kuman (Seumestri dan Alaerts, 1987).

\section{KESIMPULAN DAN SARAN}

\subsection{Kesimpulan}

Dari hasil penelitian, tujuan dan pembahasan dapat disimpulkan sebagai berikut :

1. Perbaikan kualitas air hujan dapat dilakukan dengan proses mineralisasi dan desinfeksi.

2. Kualitas air hujan terbaik terjadi pada komposisi media batuan kapur : pecahan genteng dengan perbandingan $45 \mathrm{~cm}: 45 \mathrm{~cm}$.
3. Dosis terbaik pada penurunan total coli terjadi pada dosis 30ml/1 dengan efisiensi penurunan hingga $100 \%$.

\subsection{Saran}

1. Untuk mengolah air hujan menjadi air bersih dapat menggunakan proses mineralisasi dan desinfeksi sebagai salah satu alternative yang dapat digunakan.

2. Untuk skala besar, dimensi alat dapat diperbesar sesuai dengan kapasitas yang diperlukan.

3. Untuk penelitian lebih lanjut, pada proses mineralisasi komposisi media bisa diganti dengan media lain yang sesuai dengan perbaikan konsentrasi parameter air bersih.

\section{DAFTAR PUSTAKA}

Alaerts G \& Sri Sumestri, 1987, Metoda Penelitian Air, Usaha Nasional, Surabaya.

Al-layla M.A.S, Ahmad dan E.J Midlebooks 1997, Water Supplay Engineering Design, Ann Arbor Science Publiser, inc. Michigan.

Chotib, 1994, Pengolahan Fisik Kimia dan Biologi, ITB, Bandung.

Djoko Sasongko, 1991, Pedoman Bidang Studi Pengawasan Pencemaran Lingkungan Fisik, Jakarta. 
Fardiaz, S., 1992, Polusi Air dan Udara, Penerbit Kanisius, Yogyakarta.

Hammer J.J., 1986, Technology Water and Waste Water Treatment, Me Graw Hill Book Company, New York.

Lewis, 1980, Water Quality and

Treatment, $3^{\text {th }}$ Edition, Mc

Graw-Hill Book Company,

New York.

Husain Muhammad, 2007,

Pengolahan Air Hujan Secara

Filtrasi, Mineralisasi dan

Desinfeksi sebagai Alternatif

Air Bersih. Sekolah Tinggi

Teknik Lingkungan "Yayasan

Lingkungan Hidup"

Yogyakarta.

Tjokrokusumo, KRT. Ir. 1995.

"Pengantar Enjiniring

Lingkungan". Sekolah Tinggi

Teknik Lingkungan "Yayasan

Lingkungan Hidup"

Yogyakarta.

Winarno, 1986, Air Untuk Industri

Pangan, Penerbit Gramedia,

Jakarta.

Wuryadi, 1991, Kualitas Air, Pusat

Antar Universitas Pangan dan

Gizi, UGM Yogyakarta

Laboratorium Teknik Lingkungan

Sekolah Tinggi Teknik

Lingkungan "YLH"

Yogyakarta. https://advancebpp.wordpress.com/ta g/kandunga-fe-dalam-air/ , diakses 25 November 2014

http://id.wikipedia.org/wiki/Kabupat en_Bantul , diakses 28 November 2014

http://id.wikipedia.org/wiki/Kesadah an_air diakses, 28 November 2014 http://obdum.blogspot.com/2010/10/t anah-liat.html, diakses 29 November 2014

http://pemerintahdesabanguntapan.bl ogspot.com/2013/01/sejarahterbentuknya-desabanguntapan.html, diakses 6 Desember 2014

http://ptbudie.wordpress.com/2010/0 5/31/mineral-lempung/, diakses 14 Desember 2014

http://ruangkumemajangkarya.wordp ress.com/2012/01/21/mengen al-tanah-liat-atau-lempung/, diakses 19 Desember 2014 http://s2ku.wordpress.com/2012/03/0 5/gambar-siklus-hidrologi/ , diakses 19 Desember 2014 http://elpanuryawanwayan.blogspot.com/2012/05/param eter-kimia-kualitas-air.html?m=1, diakses 30 juni 2015 http://chemistry06lieva.blogspot.com/2009/11/kesadah an-air_18.html?m=1, diakses 30 juni 2015 